Original Article

\title{
NEPHROPROTECTIVE ACTIVITY OF THE ETHNOMEDICINAL PLANTS CAESALPINIA BONDUC AND MOMORDICA DIOICA FROM NE INDIA AGAINST CISPLATIN INDUCED CHEMOTHERAPEUTIC TOXICITY
}

\author{
ANINDITA TALUKDAR ${ }^{a^{*}}$, RANJAN DUTTA KALITA ${ }^{b}$, NILAKSHI GOHAINc, KANDARPA SAIKIAa, MOHAN CHANDRA \\ KALITAc
}

aDepartment of Bioengineering and Technology, Gauhati University, Assam, India, bepartment of Applied Biology, University of Science and Technology, Meghalaya, 'Department of biotechnology, Gauhati University, Assam, India

Email: ani_bt2006@yahoo.com

Received: 22 Nov 2017 Revised and Accepted: 08 May 2018

\section{ABSTRACT}

Objective: Cisplatin a potent anticancer drug is used for treatment against different forms of cancer. However a major limitation of cisplatin is its nephrotoxicity and severe side effects. The main objective of the present study was to investigate the nephroprotective activity of the medicinal plants Caesalpinia bonduc and Momordica dioica against cisplatin-induced nephrotoxicity.

Methods: In the present study wistar rat models were intraperitoneally injected with cisplatin for eight consecutive days Plant extracts of different compositions were administered for eight days after injection of cisplatin. The polyphenolic content of the crude extracts was investigated using the Folin Ciocalteau method while the flavonoid estimation was carried out using the aluminium chloride method. The antioxidant activities of the extracts were assayed using the DPPH radical scavenging method. Plant extracts were tested for their nephroprotective ability using modified Berthelot method, uricase method, alkaline picrate method.

Results: In the present study it was found that the level of creatinine, urea, uric acid and blood urea nitrogen was lowered by the crude hexane extract of Momordica dioica and ethyl acetate extract of Caesalpinia bonduc as compared to the control group. The total phenolic content and the total flavonoid content was found to be highest in the hexane extract of Momordica dioica with $110.51 \pm 1.0 \mu \mathrm{g} / \mathrm{GAE}$ and $1.92 \pm 0.15 \mu \mathrm{g} / \mathrm{QE}$. The methanol extract of Caesalpinia bonduc was found to be the highest in inhibition of the DPPH free radicals with nearly $80 \%$ inhibition.

Conclusion: The present study revealed the nephroprotective ability of the hexane extract of Momordica dioica and ethyl acetate extract Caeselpinia bonduc. The extracts were also found to have higher antioxidant activity and therefore their nephroprotective activity might be due to attenuation of oxidative stress.

Keywords: Antioxidant activity, Nephrotoxicity, Caesalpinia bonduc, Momordica dioica, cisplatin, Nephroprotective

(c) 2018 The Authors. Published by Innovare Academic Sciences Pvt Ltd. This is an open access article under the CC BY license (http://creativecommons.org/licenses/by/4.0/) DOI: http://dx.doi.org/10.22159/ijpps.2018v10i6.23852

\section{INTRODUCTION}

Medicinal plants since ancient times have been one of the most widely trusted sources of medicine for treatment of a variety of ailments of the human body. In the fight against different diseases, medicinal plants in different forms have been used. In recent times the mechanism of many of the medicinal plants has been reported for various diseases which enhance their increased acceptance among the population. Plants have also been reported for their protective abilities against several side effects from various synthetic drugs. Such synthetic drugs have serious implications in the functioning of liver and kidneys whose diseases are a major health concern of modern day $[1,2]$. These diseases are caused by exposure to highly toxic chemicals, medications, xenobiotics etc which occur as a result of oxidative stress due to the release of high quantities of free radicals $[3,4]$. In terms of medication, the drug, cisplatin, which is widely used in a variety of treatment process against several forms of cancer, is also a major cause of kidney malfunctioning. Cisplatin is used in the treatment of solid tumors of the head, neck, ovary, breasts, lung and testicular cancer [5]. However, the major limitation of cisplatin is its ototoxic and nephrotoxic activity which limits its effectiveness. The tubular epithelial cells of the proximal tubules of the kidneys accumulate cisplatin leading to nephrotoxicity. Nephrotoxicity is characterized by cellular necrosis, destruction of intracellular organelles, mitochondrial vacuolization etc. Cisplatin has also been observed to cause lipid peroxidation, inhibition of protein synthesis and mitochondrial damage. The nephrotoxic activities of cisplatin are caused due to a variety of activities such as, DNA damage and production of reactive oxygen species. Cisplatin also inhibits the activities of the antioxidant enzymes and induces depletion of glutathione (GSH) [6-8]. Therefore plants having high antioxidant properties are believed to provide protective abilities to the kidneys against different drug-induced nephrotoxicity [9].

In the present study, the medicinal plants Caesalpinia bonduc and Momordica dioica were used to investigate for their protective ability of the kidney against cisplatin-induced nephrotoxicity. $C$. bonduc, a herb belonging to Caesalpiniaceae family, which is prevalent all over India and is used in the traditional system of medicine for treatment of a variety of disorders viz, antiinflammatory, antioxidant, antitumour, antimalarial, antidiabetic, adaptogenic and anthelmintic $[10,11]$. $M$. dioica is a climber of the Cucurbitaceae family, extensively used in Indian system of traditional medicine as a natural source for treatment of a variety of disorders which includes hepatic diseases, diabetes, ulcer etc [12]. Besides, nutritionally the plant is a rich source of protein. It also contains lipid, calcium, crude fiber, iron, carbohydrate and phosphorous. It has also been reported that among all the cucurbitaceous family $M$. dioica contains the highest amount of carotene [13]. The present study details the methanol, ethyl acetate and hexane extracts obtained from both the plants and their investigation as nephroprotective agents in Wistar rats.

\section{MATERIALS AND METHODS}

\section{Plant materials}

The rhizome of Momordica dioica were collected in the month of January-February 2014 from Kamrup district (Latitude-26.3160819, 
Longitude-91.5983959) located in Assam, North East India and seeds of Caesalpinia bonduc were collected in the month of February 2014 from Dhemaji district (Latitude-27.608731, Longitude94.7691586) located in Assam, North East of India. A Herbarium voucher specimen was prepared and submitted for identification. The voucher specimen numbers of the plants are Herb./Bot./ GU/2016/175 and Herb./Bot./GU/2016/198.

\section{Chemicals}

Rutin, Quercetin, Aluminium chloride, 2, 2-diphenyl-1-picrylhydrazyl, trisodium citrate, triton x 100 were obtained from Sigma Aldrich. Cisplatin, silymarin, ascorbic acid, methanol, acetone, ferrous chloride and ferric chloride were purchased from Merck. All other reagents were of analytical grade.

\section{Extract preparation}

Plant materials were properly cleaned, shade dried at room temperature and grinded to make a fine powder. Extracts were prepared in three different solvents according to the polarity low to high i.e. hexane $(\mathrm{H})$, ethyl acetate (E) and methanol (M) using soxhlet apparatus, which was then concentrated in a rotary evaporator and stored at $4{ }^{\circ} \mathrm{C}$ for further use.

\section{Preliminary phytochemical analysis}

The extracts of Momordica dioica and Caesalpinia bonduc were subjected to preliminary phytochemical analysis [14], testing for the detection of different chemical groups of compounds. Air-dried and powdered plant materials were screened for the presence of, total phenols and flavonoids. [15-17].

\section{Qualitative phytochemical activity assay}

\section{Determination of total phenolic content}

Phenolic compounds are plant secondary metabolites produced either from phenylalanine or from its precursor shikimic acid [14]. The phenolic compounds are capable of the direct chain breaking antioxidant action by free radical scavenging. Total phenolic content of the extracts was determined using Folin-Ciocalteau method with some modifications [18]. Total phenolic content is expressed at 0.1 $\mathrm{mg} / \mathrm{g}$ gallic acid equivalent using the following equation based on calibration curve, $\mathrm{y}=0.1216 \mathrm{x}$ where $\mathrm{x}=\mathrm{absorbance}$ and $\mathrm{y}=$ gallic acid equivalent $(\mu \mathrm{g} / \mathrm{g})[19]$.

\section{Determination of total flavonoid content}

The aluminium chloride method was used for the determination of the total flavonoid content of the extracts [17]. Absorbance at 415 $\mathrm{nm}$ was recorded after $30 \mathrm{~min}$ of incubation. A standard calibration plot was generated at $415 \mathrm{~nm}$ using known concentrations of quercetin. The concentrations of flavonoid content were be calculated as quercetin $\mathrm{mg} / \mathrm{g}$ using the following equation based on calibration curve, $\mathrm{y}=0.0255 \mathrm{x}$ where $\mathrm{x}$ was absorbance and $\mathrm{y}$, was the quercetin equivalent $(\mu \mathrm{g} / \mathrm{g})$.

\section{Determination of total in vitro antioxidant activity}

\section{Free radical scavenging activity (DPPH assay)}

The percentage of antioxidant activity of each substance was assessed by DPPH free radical assay. The free radical scavenging activity for DPPH radicals by both the plant extracts was measured by the following method [18]. Assays were performed in $300 \mathrm{ml}$ reaction mixtures, containing $200 \mathrm{ml}$ of $0.1 \mathrm{mmol} \mathrm{DPPH}$ ethanol solution; $90 \mathrm{ml}$ of $50 \mathrm{mmol}$ Tris-HCl buffer (pH 7.4), $10 \mathrm{ml}$ of ethanol (as solvent blank) or test plant extracts and ascorbic acid were used as positive controls. After $30 \mathrm{~min}$ of incubation at room temperature, absorbance $(540 \mathrm{~nm})$ of the reaction mixtures was taken by UV spectrophotometer [19]. All determinations were performed in triplicate. The inhibitory effect of DPPH scavenging (in \%) was calculated according to the following formula:

$$
\%=\left(A_{\text {control }}-\mathrm{A}_{\text {sample }}\right) /\left(\mathrm{A}_{\text {control }}\right) \times 100
$$

Where $A_{\text {control }}$ is the absorbance of the control which contains all reagents without the extract and $A_{\text {sample }}$ is the absorbance of the sample analyzed.

\section{In vivo animal study \\ Standardization of animal model}

Healthy adult wistar rats (Purchased from College of Veterinary Science, Khanapara, Guwahati, Assam) of either sex approximately of the same age, weighing between 190-220 g and kept in a controlled environment were used for the study. The animals were group housed in polypropylene cages containing sterile paddy husk bedding under controlled conditions at $25 \pm 2{ }^{\circ} \mathrm{C}, \mathrm{RH} 50 \pm 5 \%$ and natural light (10/14 h of light/dark cycles). Food and water were provided at regular interval. The food was withdrawn 18-24 hour before the experiment, though the water was added ad libitum. The study was conducted after obtaining the approval of the Institutional Animal Ethics Committee (No: IAEC/PER/2016/2017-3).

\section{Acute toxicity studies}

The acute oral toxicity of the plant extracts was estimated by following up-and-down staircase method in wistar rat as per OECD TG 425 guidelines. Based on the toxicity study, the doses of plant extract were selected.

\section{Drugs and selection of doses}

Cisplatin (Merck, India) was used as a nephrotoxic agent and silymarin (Merck, India) was used as a standard drug in the present study. The doses were selected on the basis of the relevant previous studies [19]. Plant extracts were given orally as 100 and $200 \mathrm{mg} / \mathrm{kg}$ doses for the treated group half an hour prior to the treatment of cisplatin toxicity $(8 \mathrm{mg} / \mathrm{kg}$, i. p.), silymarin $(8 \mathrm{mg} / \mathrm{kg})$ was used as standard drug for the standard group and for the control group vehicle (distilled water) was used prior to the cisplatin injection $[19,20]$.

\section{Estimation of the nephroprotective activity of the crude extracts}

The crude plant extracts were tested for their nephroprotective ability. In this experiment wistar Albino rat models were used for the in vivo study. In each group, 6 numbers of animals were taken $(\mathrm{n}=6)$. Two different doses of the extracts, $100 \mathrm{mg} / \mathrm{Kg}$ body weight and $200 \mathrm{mg} / \mathrm{Kg}$ body weight, were given daily orally and cisplatin at $7.5 \mathrm{mg} / \mathrm{Kg}$ body weight was injected intraperitoneally after an hour. The positive control, silymarin taken at a concentration of 14.5 $\mathrm{mg} / \mathrm{Kg}$ body weight was also given orally. Normal saline was given to the negative control group. The study was carried out for five days in which all the doses including the extract and cisplatin was repeated daily $[19,20]$. The animals were sacrificed on the $6^{\text {th }}$ day. Blood were collected following the CPCSEA guidelines. Different biochemical estimation of the various markers of the kidney diseases like BUN (Blood Urea Nitrogen) test, urea test, uric acid and serum creatinine test were carried out to estimate the toxicity parameters of cisplatin and the plant extracts $[17,21,22]$.

\section{Statistical analysis}

Triplicate analyses were performed on a number of samples, established according to the total plant samples investigated and element analyzed. For an assessment of the analytical relevance of the results, standard procedures of statistical calculation were used. All numerical data were expressed as mean \pm standard deviation $($ mean $\pm S D)$ of three replicates $(n=3)$ without a significant statistical difference $(\mathrm{p}<0.05)$. Experiments were analyzed by one-way analysis of variance followed by Tukey's test. For statistical analysis, the commercially available software package Graph Pad Prism (Windows) was used.

\section{RESULTS}

Our present study focused on studying different phytochemical present in various extracts by different methods and identification of the phytochemicals that might be related to the nephroprotective activity. Ethnomedicinal plants used in different traditional medicine contain a high amount of various substances which can be used for the protective treatment of a variety of disorders. Secondary metabolites such as terpenoids that gives plants their odors and others metabolites (quinines and tannins) are responsible 
for plant flavor and some of the herbs and spices used by humans to season food yield useful medicinal compounds. The phenolic and flavonoid compounds are known as powerful chain-breaking antioxidants for their scavenging ability and which is due to their hydroxyl groups [17-25]. The phenolic and flavonoids compounds are the most important groups of plant secondary metabolites. Phenols are the group of compounds with potential antioxidant activity, which is believed to be mainly because of their redox properties and they play an important role in adsorbing and neutralizing free radicals. Total phenol and total flavonoid content of the hexane extract was significantly higher in $M$. dioica extract, i.e. $110.51 \pm 1.0$ ( $\mu \mathrm{g}$ Gallic acid/g of dry plant material) and $1.92 \pm 0.15$ ( $\mu \mathrm{g}$ quercetin/g of dry plant material) respectively. Total phenolic and flavonoid content of all the plant extracts are shown in table 1.

Table 1: Total phenolics and flavonoids content in different solvent extracts of Momordica dioica and Caesalpinia bonduc

\begin{tabular}{lll}
\hline Extract & Total phenol ( $\boldsymbol{\mu g}$ of GAE/g of extract) & Total Flavonoids( $\boldsymbol{\mu g}$ of QE/g of extract) \\
\hline n-Hexane extract of Momordica dioica & $110.51 \pm 1.0$ & $1.92 \pm 0.15$ \\
Ethyl acetate extract of Momordica dioica & $94.91 \pm 2.39$ & $0.35 \pm 0.06$ \\
Methanol extract of Momordica dioica & $72.11 \pm 0.5$ & $0.10 \pm 0.07$ \\
n-Hexane extract of Caesalpinia bonduc & $70.22 \pm 0.35$ & $0.01 \pm 0.14$ \\
Ethyl acetate extract of Caesalpinia bonduc & $78.11 \pm 0.44$ & $0.10 \pm 0.07$ \\
Methanol extract of Caesalpinia bonduc & $62.3 \pm 1.06$ & $0.9 \pm 0.11$ \\
\hline
\end{tabular}

Values are mean $\pm \mathrm{SD}$ of three replicates $(\mathrm{n}=3$ ); GAE-Gallic acid equivalent, $\mathrm{QE}-\mathrm{Quercetin}$ equivalent.

\section{In vitro free radical-scavenging activity}

In the present study, evaluation of the antioxidant potential of the extract was done. Earlier reports have showed the relationship between a high phenolic content and antioxidant activity and this correlation was confirmed in the present study. The percentage of total antioxidant activity of all the extracts of $M$. dioica and $C$. bonduc was estimated and the results are presented below.

\section{DPPH radical scavenging assay}

The antioxidant capacity of the extracts was measured against DPPH with increasing concentration of the solvent extracts of both the plants. Ascorbic acid was used as a the+ve control. The percentage (\%) of inhibition of the free radicals by the different extracts with an increase in the concentration of solvent extracts was calculated. The graph shown in fig. 1, 2 is obtained by plotting the \% of inhibition, calculated at an absorbance of $517 \mathrm{~nm}$ against the concentration of solvent extracts.

In vivo animal study

\section{Acute toxicity studies}

Both the plant extracts were orally fed to wistar rat to check the observations of behavioural change for $2000 \mathrm{mg} / \mathrm{kg}$ body weight of the extract. All the tested sample didn't showed any toxic effect as different parameters in this study showed all normal behaviour in the animal models as shown in table 2.

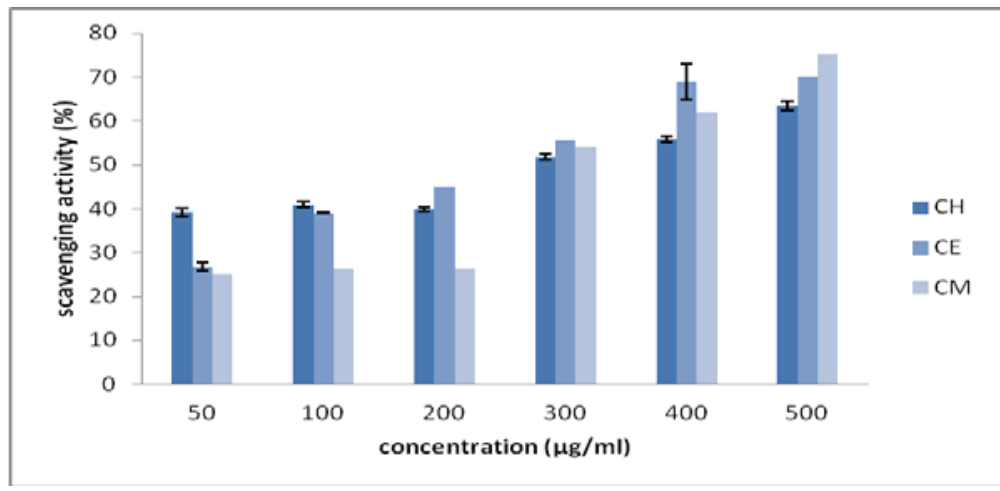

Fig. 1: DPPH scavenging activity of three extracts, CH-hexane, CE-ethyl acetate and CM-methanol extract of Caesalpinia bonduc, Values are mean $\pm S D$ of three replicates $(n=3)$

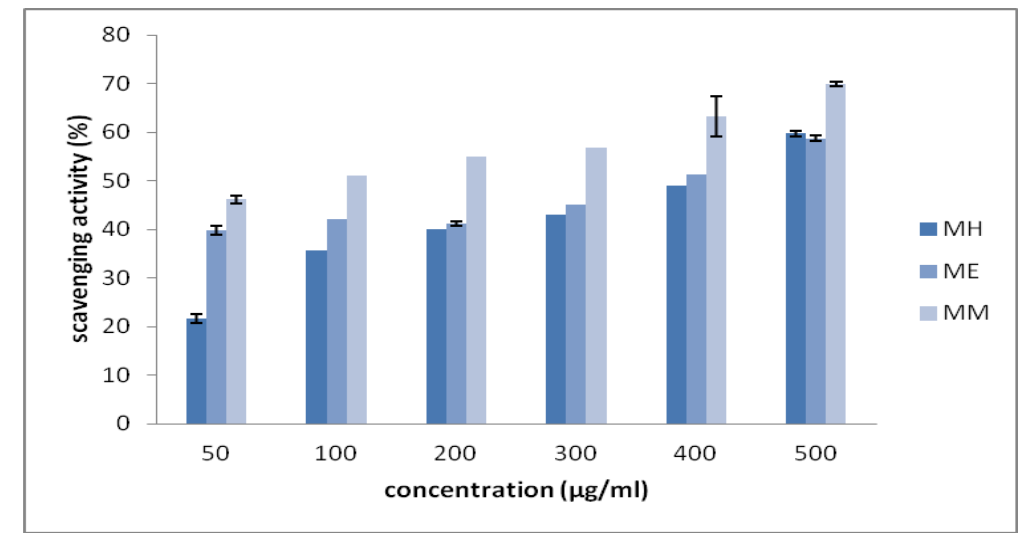

Fig. 2: DPPH scavenging activity of three extracts, MH-hexane, ME-ethyl acetate and MM-methanol extract of Momordica dioica, Values are mean $\pm S D$ of three replicates $(n=3)$ 
Table 2: Observation of behavioural change for $2000 \mathrm{mg} / \mathrm{bdw}$ of extracts

\begin{tabular}{llll}
\hline Observation parameters & Control group & & Treated groups \\
\cline { 2 - 4 } & $\mathbf{1 2 h}$ & $\mathbf{2 4} \mathbf{h}$ & $\mathbf{1 2} \mathbf{h}$ \\
\hline Eyes & Normal & Normal & Normal \\
Skin and fur & Normal & Normal & Normal \\
Mucous membrane & Normal & Normal & Normal \\
Behavioral patterns & Normal & Normal & Normal \\
Salivation & Normal & Normal & Normal \\
Lethargy & Normal & Normal & Normal \\
Sleep & Normal & Normal & Normal \\
Diarrhea & Normal & Normal & Normal \\
Coma & Not observed & Not observed & Not observed \\
Tremors & Not observed & Not observed & Not observed \\
\hline
\end{tabular}

\section{Effect of plant extract on creatinine level}

A significantly increased level of serum creatinine was observed in blood serum samples of the control in comparision to the silymarin standard group (fig. 3). However, supplementation with $M$. dioica and $C$. bonduc extract at 100 and $200 \mathrm{mg} / \mathrm{kg}$ bdw dose significantly prevented further elevations of creatinine. Highest effects were observed in $200 \mathrm{mg} / \mathrm{kg}$ bdw extract of ME extract.

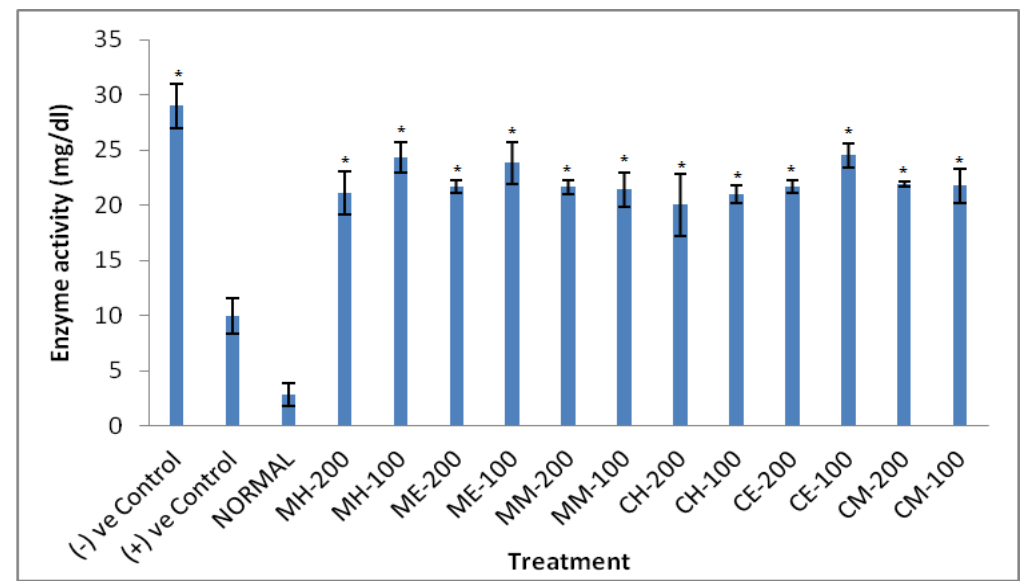

Fig. 3: Effect of the plant extracts on the Creatinine level, MH-hexane, ME-ethyl acetate, MM-methanol extract of Momordica dioica and CHhexane, CE-ethyl acetate, CM-methanol extract of Caesalpinia bonduc, Results are expressed as mean \pm SD of three replicates ( $\mathrm{n}=3$ ), * $(P<0.05)$ indicates significant increase in the enzyme activity when compared to the normal group

\section{Effect of plant extract on urea level}

A significantly increased level of serum creatinine was observed in blood serum samples of the control group in compare to the silymarin standard group [fig. 4].
However, supplementation with $M$. dioica and $C$. bonduc extract at 100 and $200 \mathrm{mg} / \mathrm{kg}$ dose significantly prevented further elevations of urea level, with higher effects observed in $100 \mathrm{mg} / \mathrm{kg}$ bdw extract of MM extract as compared to the control group.

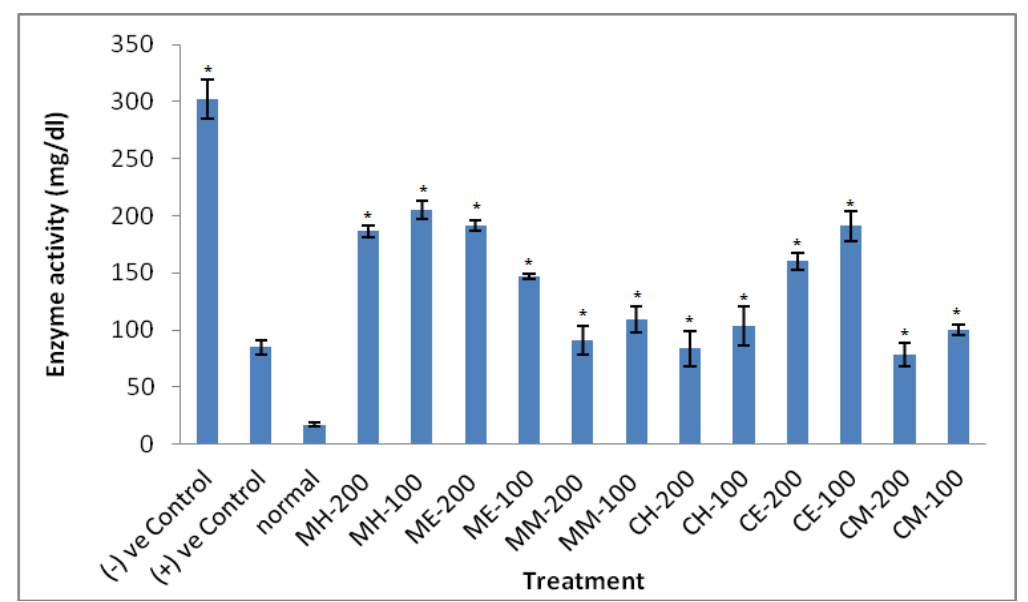

Fig. 4: Effect of the plant extracts on the urea level, MH-hexane, ME-ethyl acetate, MM-methanol extract of Momordica dioica and CHhexane, CE-ethyl acetate, CM-methanol extract of Caesalpinia bonduc, values are mean \pm SD of three replicates $(n=3), *(P<0.05)$ indicates significant increase in the enzyme activity when compared to the normal group 


\section{Effect of plant extract on blood urea nitrogen level}

A significantly increased level of serum creatinine was observed in blood serum samples of the control group in comparision to the silymarin standard group [fig 5].
However, supplementation with $M$. dioica and $C$. bonduc extract at 100 and $200 \mathrm{mg} / \mathrm{kg}$ bdw dose significantly prevented further elevations of urea level, with higher effects observed in the 200 $\mathrm{mg} / \mathrm{kg}$ extract of ME extract as compared to the control group.

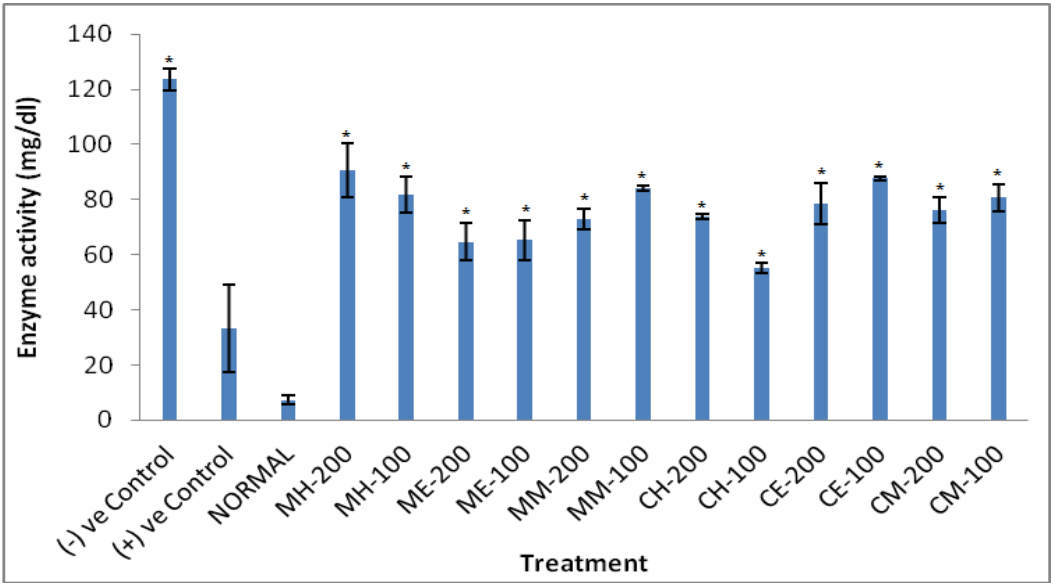

Fig. 5: Effect of the plant extracts on the Blood Urea Nitrogen level, MH-hexane, ME-ethyl acetate, MM-methanol extract of Momordica dioica and $\mathrm{CH}$-hexane, $\mathrm{CE}$-ethyl acetate, $\mathrm{CM}$-methanol extract of Caesalpinia bonduc, values are mean \pm SD of three replicates (n=3), *

$(P<0.05)$ indicates significant increase in the enzyme activity when compared to the normal group

\section{Effect of plant extract on uric acid level}

A significantly increased level of serum creatinine was observed in blood serum samples of the control group in compare to the silymarin standard group (fig. 6).
However, supplementation with $M$. dioica and $C$. bonduc extract at 100 and $200 \mathrm{mg} / \mathrm{kg}$ dose significantly prevented further elevations of the uric acid level, with higher effects observed in the $100 \mathrm{mg} / \mathrm{kg}$ bdw extract of ME extract as compared to the control group.

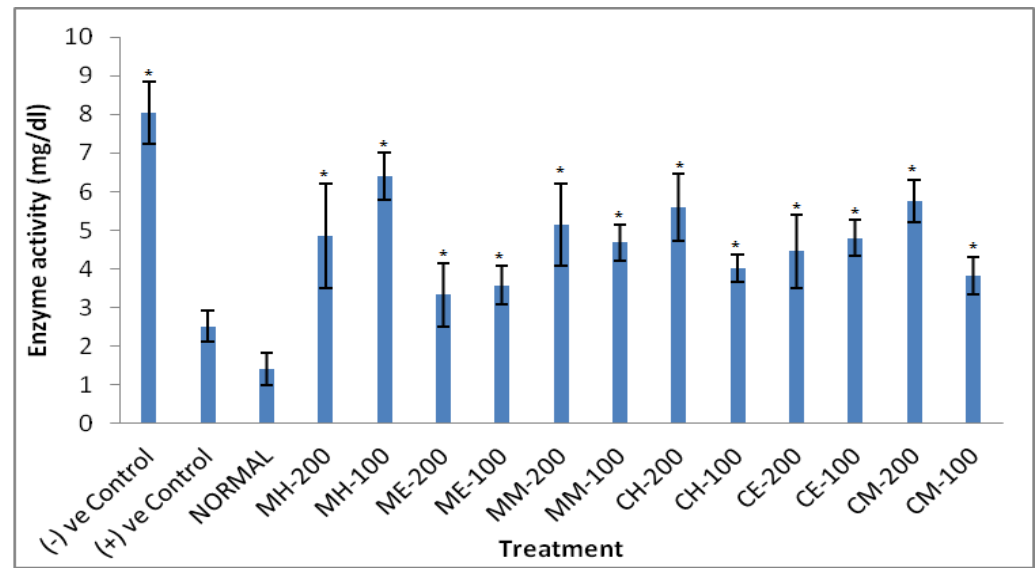

Fig. 6: Effect of the plant extracts on the Uric acid level, MH-hexane, ME-ethyl acetate, MM-methanol extract of Momordica dioica and CHhexane, CE-ethyl acetate, CM-methanol extract of Caesalpinia bonduc, values are mean \pm SD of three replicates $(\mathrm{n}=3),{ }^{*}(\mathrm{P}<0.05)$ indicates significant increase in the enzyme activity when compared to the normal group

Effect of plant extract on Serum glutamic pyruvic transaminase (SGOT) level

A significantly increased level of serum creatinine was observed in blood serum samples of the control group in compare to the silymarin standard group [fig. 7]. However, supplementation with $M$. dioica and $C$. bonduc extract at 100 and $200 \mathrm{mg} / \mathrm{kg}$ dose significantly prevented further elevations of uric acid level, with higher effects observed in the $100 \mathrm{mg} / \mathrm{kg}$ bdw extract of ME extract as compared to the control group.

Effect of plant extract on serum glutamic-oxaloacetic transaminase (SGPT) level

A significantly increased level of serum creatinine was observed in blood serum samples of the control group as compared to the silymarin standard group [fig. 8]. However, supplementation with $M$. dioica and $C$. bonduc extract at 100 and $200 \mathrm{mg} / \mathrm{kg}$ dose significantly prevented further elevations of uric acid level, with higher effects observed in the $200 \mathrm{mg} / \mathrm{kg}$ bdw extract of ME extract as compared to the control group.

\section{Effect of plant extract on alkaline phosphatase level}

A significantly increased level of alkaline phosphatase was observed in blood serum samples of the control group in comparison to the silymarin standard group [fig 9].

However, supplementation with $M$. dioica and $C$. bonduc extract at 100 and $200 \mathrm{mg} / \mathrm{kg}$ dose significantly prevented further elevations of alkaline phosphatase level, with higher effects observed in the 200 $\mathrm{mg} / \mathrm{kg}$ bdw extract of ME extract as compared to the control group. 


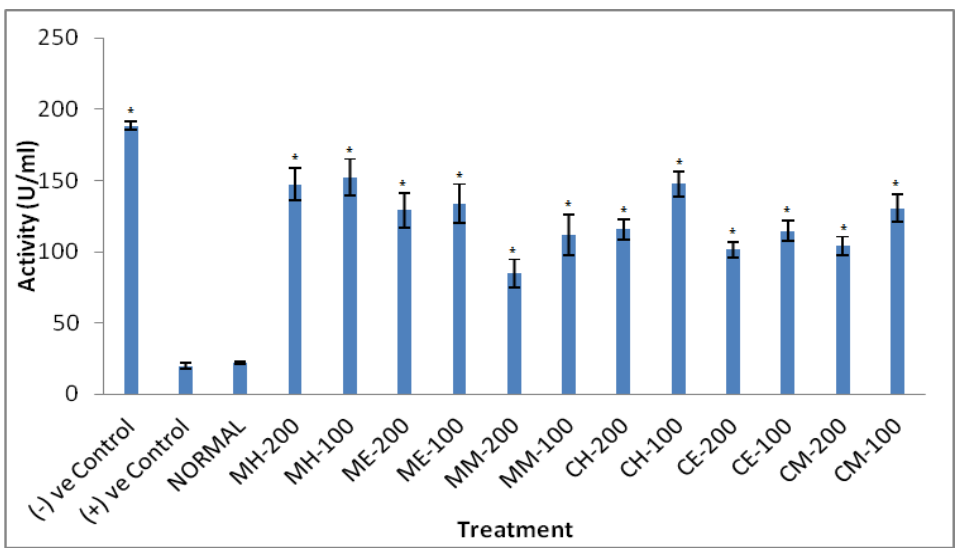

Fig. 7: Effect of the plant extracts on the SGOT level, MH-hexane, ME-ethyl acetate, MM-methanol extract of Momordica dioica and CHhexane, CE-ethyl acetate, CM-methanol extract of Caesalpinia bonduc, Values are mean \pm SD of three replicates $(n=3),{ }^{*}(P<0.05)$ indicates significant increase in the enzyme activity when compared to the normal group

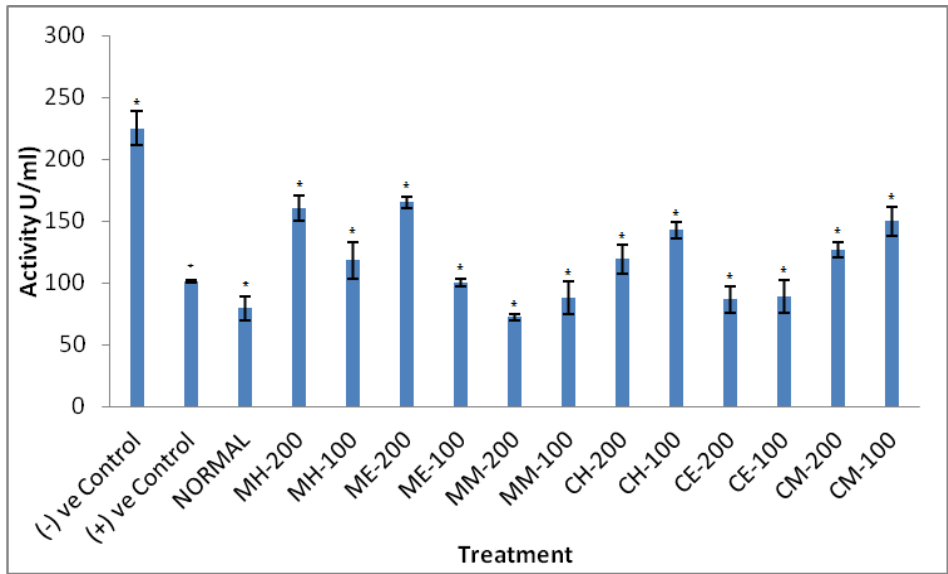

Fig. 8: Effect of the plant extracts on the SGPT level, MH-hexane, ME-ethyl acetate, MM-methanol extract of Momordica dioica and CHhexane, CE-ethyl acetate, CM-methanol extract of Caesalpinia bonduc, values are mean \pm SD of three replicates $(n=3),{ }^{*}(P<0.05)$ indicates significant increase in the enzyme activity when compared to the normal group

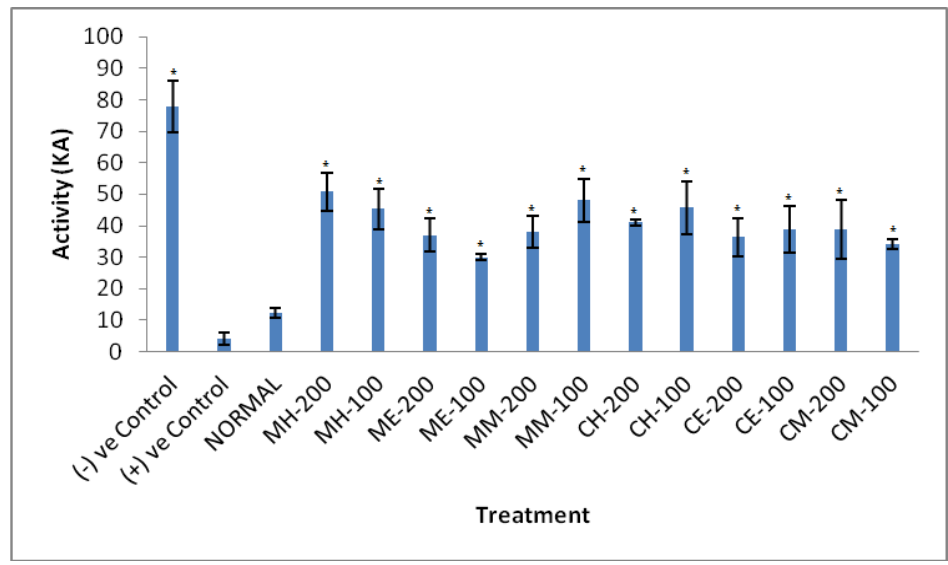

Fig. 9: Effect of the plant extracts on the Alkaline phosphatase level, MH-hexane, ME-ethyl acetate, MM-methanol extract of Momordica dioica and CH-hexane, CE-ethyl acetate, CM-methanol extract of Caesalpinia bonduc, values are mean \pm SD of three replicates ( $\mathrm{n}=3$ ), *

$(P<0.05)$ indicates significant increase in the enzyme activity when compared to the normal group

\section{DISCUSSION}

The plant crude extracts of the Caesalpinia bonduc and Momordica dioica tested for the phytochemical analysis and it showed the presence of many important phytochemicals. Phenols and flavonoids were present in all of the plant extracts whereas saponins, steroids were absent.
Quantitative analysis of total phenolics and flavonoids in the plant extracts of Caesalpinia bonduc and Momordica dioica showed that hexane extract of Momordica dioica contained highest amount of phenolics i.e. $110.51 \pm 1.0$ ( $\mu \mathrm{g}$ Gallic acid/g of dry plant material) and flavonoids $1.92 \pm 0.15$ ( $\mu \mathrm{g}$ quercetin/g of dry plant material) and ethyl acetate extract of Caesalpinia bonduc contained the highest 
amount of phenolics i.e. $78.11 \pm 0.44$ ( $\mu$ g Gallic acid/g of dry plant material and flavonoids $0.10 \pm 0.07$ ( $\mu$ g quercetin/g of dry plant material) (table 1).

The antioxidant activity of Caesalpinia bonduc and Momordica dioica was determined by measuring the capacity to scavenge free radicals. In case of both the plant extracts showed increasing antioxidant property as the concentration increases, the highest antioxidant activity was shown by methanol extracts which demonstrated more than $70 \%$ of activity. Standard drug ascorbic acid showed $97.5 \%$ inhibition at the same highest concentration. Thus the scavenging activities of the plant extracts of both the plants were very promising as it showed almost equivalent activity to ascorbic acid.

The plant extracts does not show any abnormalities after the treatment of all the extracts for the in vivo study for the behavioral experiment. The in vivo study for the nephroprotective activity clearly shows good nephro protectivity against the cisplantin induced toxicity which is in correlation with the high phenolics and high antioxidant activity. The level of creatinine, urea, uric acid and blood urea nitrogen was higher in the cisplatin-treated group whereas the biochemical marker are lowered by the ethyl acetate crude extract of Momordica dioica and ethyl acetate extract of Caeselpinia bonduc in comparision to the control group, which shows better nephro-protectivity in compare with the results shown by ethanol extract of $S$. hypericifolia against paracetamol induced nephrotoxicity [2]. The hydro alcoholic extract of $P$. zeylanica showed better prevention against cisplatin-induced renal damage by significantly reducing the elevated levels of urea, creatinine and uric acid in serum [5]. However serum SGOT, SGPT and alkaline phosphatise level of Momordica dioica and Caeselpinia bonduc treated samples demonstrated higher protectivity against cisplatininduced nephrotoxicity than that of cisplatin and was comparable to the standard drug silymarin.

\section{CONCLUSION}

In conclusion, the result of the present study shows that the in vitro antioxidant study of both the plant extracts showed significant scavenging free radical activity. However, the study shows that the plant extracts of Momordica dioica and Caeselpinia bonduc have huge potential as a source of natural antioxidant. The ethyl acetate extracts of Momordica dioica and Caeselpinia bonduc have good flavonoid and phenolics content. This investigation of the in vivo nephroprotective study demonstrated the significant nephroprotective role of both the extracts of Caeselpinia bonduc and Momordica dioica. Higher nephroprotectivity was observed in the extract of Momordica dioica as compared to Caeselpinia bonduc. It may be possible that compounds with a high polarity such as phenolics and flavonoids are present in the plant extracts, which may be the possible reasons responsible for the nephroprotective activity. Our study also demonstrated that of both the potent plant extracts, none of the extracts showed any toxic activity as observed through the behavioural change test. Therefore the present study suggests that the plant Momordica dioica might be a potential source of natural antioxidant and nephroprotective agent and it makes the plants suitable as a drug candidate.

\section{ACKNOWLEDGEMENTS}

The authors are thankful to Department of Biotechnology (DBT) for providing the financial support.

\section{AUTHORS CONTRIBUTIONS}

The author AT, RDK carried out the work and wrote the manuscript. NG helped in performing some of the experiments. KS and MCK supervised the work.

\section{CONFLICTS OF INTERESTS}

All authors have none to declare any conflicts of interest

\section{REFERENCES}

1. Panda S, Naik R. Evaluation of cardioprotective activity of Ginkgo biloba and Ocimum sanctum in rodents. Altern Med Rev 2009;14:161-71.
2. Alqasoumi I. Evaluation of the hepatroprotective and nephroprotective activities of Scrophularia hypericifolia growing in Saudi Arabia. Saudi Pharm J 2014;22:258-63.

3. Marina N. Hepatotoxicity of antiretrovirals: incidence, mechanisms and management. J Hepat 2006;44:132-9.

4. Abubaker S, Shanmukha I, Rajendra V, Ramachandra S. Protective effect of Spathodea campanulata bark against paracetamol-induced nephrotoxicity in rats. Int J PharmTech Res 2012;4:398-403.

5. Rajakrishnan R, Lekshmi R, Benil B, Thomas J, Farhan $\mathrm{H}_{\text {, }}$ Rakesh V. Phytochemical evaluation of roots of Plumbago zeylanica $L$. and assessment of its potential as a nephroprotective agent. Saudi J Biol Sci 2017;24:760-6.

6. Mathew S, Joseph A, Srinivasan K, Dinakaran V, Mantri A, Movaliya V. Effect of ethanol extract of Sphaeranthus indicus on cisplatin-induced nephrotoxicity in rats. Nat Prod Res 2012;26:933-8.

7. Leibbrandt E, Wolfgang H, Metz L, Ozobia A, Haskins R. Critical subcellular targets of cisplatin and related platinum analogs in rat renal proximal tubule cells. Kidney Int 1995;48:761-70.

8. Matsushima H, Yonemura K, Ohishi K, Hishida A. The role of oxygen free radicals in cisplatin-induced acute renal failure in rats. J Lab Clin Med 1998;131:518-26.

9. Peng A, Lin Y. Herbal treatment for renal diseases. Annals Acad Med 2005;34:44-51.

10. Manikandaselvi S, Vadivel V, Brindha P. Caesalpinia bonducella L.: a nutraceutical plant. J Chem Pharm Res 2015;7:147-52.

11. Khan N, Kumar S, Singh P, Dhankhar N. A pharmacognostic and pharmacological overview on Caesalpinia bonducella. Res J Pharm Biol Chem Sci 2012;3:480-96.

12. Noorani A, Gupta A, Bhadada K, Kale K. Protective effect of methanolic leaf extract of Caesalpinia Bonduc (L.) on gentamicin-induced hepatotoxicity and nephrotoxicity in rats. Iranian J Pharma Ther 2010;10:21-5.

13. Manimala M, Karpagam S, Deecaraman, Atlee C, Prabhu P. Evaluation of nephroprotective and antioxidant activity of ethanolic extracts of Momordica dioica leaves. Pharm Lett 2015;7:153-6.

14. Talukdar N, Hossain N. Phytochemical, phytotherapeutical and pharmacological study of Momordica dioica. Evid Based Complement Alternat Med 2014;11:45-51.

15. Harborne B. Phytochemical screening- a guide to modern techniques of plant analysis. Chapman Hall New York; 1991. p. 653-8.

16. Anna N. Antioxidant studies on selected Lamiaceae herbs in vitro and in humans. University Press: Helsinki Finland; 2008. p. $952-78$.

17. Wolve $\mathrm{K}, \mathrm{Wu} \mathrm{X}$, Spitz R. Telomere dysfunction: a potential cancer predisposition factor. J Natl Cancer Inst 2003; 95:1211-8.

18. Ordon E, Gomez D, Vattione A, Isla L. Anti-oxidant activities of Sechium edule (Jacq) swart extracts. Food Chem 2006;97:452-8.

19. Chirino Y, Rogelio H, Chaverri J. Peroxynitrite decomposition catalyst ameliorates renal damage and protein nitration in cisplatin-induced nephrotoxicity in rats. J BMC Pharmacol 2004:4:20-9.

20. Kunihiko S, Kazuto M, Kazutaka M, Yoshinori I, Kazuhiko T, Hideki H. Protection by a radical scavenger edaravone against cisplatin-induced nephrotoxicity in rats. Eur J Pharmacol 2002;2:203-8.

21. Luania M, Greggi A, Darin J. Effects of the antioxidants curcumin or selenium on cisplatin-induced nephrotoxicity and lipid peroxidation in rats. Pharmacol Res 2001;43:145-50.

22. Satu M, Husain K, Gary L, Leonard P. Dose-dependent protection by lipoic acid against cisplatin-induced nephrotoxicity in rats: antioxidant defense system. Basic Clin Toxicol Pharmacol 2000;86:234-41.

23. Robert $R$, Nicoletta $P$. Antioxidant activity applying an improved ABTS radical cation decolourization assay. Free Radical Biol Med 1999;26:1231-7.

24. Rajendiran D, Packirisamy S, Gunasekaran K. A review on the role of antioxidants in diabetes. Asian J Pharm Clin Res 2018;11:48-53. 
25. Priya G. Antioxidant mediated defence role of Eclipta alba herbal extract against ccl4 induced toxic hepatitis. Int J Curr Pharm Res 2018;10:29-32.

26. Sivakumar T, Sundaram B, Kamaraj L, Periyanaina K, Chaiyavat C. Evaluation of bioactivities of Morinda tinctoria leaves extract for pharmacological applications. Asian J Pharm Clin Res 2018;11:100-5.

27. Mayura K, Suparna B, Pratima K. Role of antioxidants and nutrition in oxidative stress: a review. Int J Appl Pharm 2015;7:1-4. 